\title{
KEANEKARAGAMAN JENIS BINTANG LAUT DI PANTAI BAHOWO KECAMATAN BUNAKEN KOTA MANADO SULAWESI UTARA
}

\author{
Putri Binambuni ${ }^{1)}$, Marnix Langoy ${ }^{1)}$, Deidy Y. Katili ${ }^{1)}$ \\ ${ }^{1)}$ Jurusan Biologi, FMIPA Unsrat Manado, 95115
}

\begin{abstract}
Indonesia's territory has high water resources such as fauna diversity. One animal example from the Phylum Echinodermata Class Asteroidea. This is supported by the presence of sand, seagrass and coral reef habitats. Asteroidea is a inhabitant of shallow waters and is commonly found in seagrass beds and coral reefs. This study aims to analyze the diversity of sea star species in Bahowo Beach, Bunaken District, Manado City, North Sulawesi. The sampling method used in this study is the line transect and squared method. Analysis of the data used is Relative Abundance (KR), Diversity Index $\left(H^{\prime}\right)$, Evenness Index (e), and Wealth Index $(R)$. The results of the study found 5 species with a total of 73 individuals. Diversity index value is $H^{\prime}=1.23$ and shows the results of moderate diversity.
\end{abstract}

Keywords: Diversity of Types of Sea Stars in Bahowo Beach, Bunaken District, Manado City, North Sulawesi.

\begin{abstract}
ABSTRAK
Wilayah Indonesia memiliki sumber daya perairan yang tinggi seperti keanekaragaman fauna. Salah satu contoh hewan dari Filum Echinodermata Kelas Asteroidea. Hal ini didukung oleh keberadaan habitat pasir, padang lamun, dan terumbu karang. Asteroidea adalah penghuni perairan dangkal dan umumnya terdapat di padang lamun dan terumbu karang. Penelitian ini bertujuan untuk menganalisis keanekaragaman jenis bintang laut yang ada di Pantai Bahowo, Kecamatan Bunaken, Kota Manado, Sulawesi Utara. Metode pengambilan sampel yang diigunakan dalam penelitian ini adalah metode garis transek dan kuadrat. Analisis data yang digunakan yaitu Kelimpahan Relatif (KR), Indeks Keanekaragaman (H'), Indeks Kemerataan (e), dan Indeks Kekayaan (R). Hasil penelitian didapatkan 5 spesies dengan jumlah 73 individu. Nilai indeks keanekaragaman yaitu $H^{\prime}=1,23$ dan menunjukkan hasil keanekaragaman sedang.
\end{abstract}

Kata Kunci: Keanekaragaman Jenis Bintang Laut di Pantai Bahowo, Kecamatan Bunaken, Kota Manado, Sulawesi Utara. 


\section{PENDAHULUAN}

Bintang laut yang hidup di dunia saat ini diperkirakan sekitar 1800 jenis, yang termasuk kedalam kelas Asteroidea, yang terdiri dari 4 bangsa (ordo), 26 suku (famili), dan 144 marga (genus). Di perairan Indonesia diperkirakan terdapat sekitar 400 spesies bintang laut (Asteroidea) atau sekitar $22 \%$ dari jumlah total bintang laut di dunia (Clark dan Rowe, 1971). Untuk kedalaman 0 m sampai dengan $20 \mathrm{~m}$ di perairan Indonesia, terdapat sekitar 88 spesies bintang laut yang termasuk ke dalam 38 genus dan 17 famili (Iken et al., 2010).

Tubuh bintang laut diolah dan dimanfaatkan untuk menghasilkan senyawa glikosida yang berguna sebagai bahan antibiotik (Susantie, 1997). Dalam jaring makanan bintang laut merupakan salah satu yang berperan penting, umumnya sebagai predator dan pemakan detritus. Penelitian tentang bintang laut belum banyak diteliti di Indonesia (Puspitasari et al., 2012), lebih banyak penelitian tentang bintang laut dilaporkan dan diteliti di negara-negara lain seperti Australia dan Jepang dibandingkan di Indonesia (Aziz, 1996). Beberapa

\section{METODE PENELITIAN}

Penelitian dilaksanakan bulan Juni 2018 jam 10.00 sampai selesai di Pantai Bahowo Kecamatan Bunaken, Kota Manado, Sulawesi Utara. Alat dan bahan yang digunakan yaitu tali plastik, patok kayu, alat tulis menulis (papan clipboard, pensil, dan kertas), meteran, kamera, termometer, salinometer, kertas lakmus, petak kuadrat berukuran $1 \mathrm{~m} \quad \mathrm{x} \quad 1 \mathrm{~m}$. Pengambilan sampel dilakukan dengan penelitian tentang bintang laut yang telah dilakukan di Sulawesi Utara diantaranya di perairan Pantai Desa Mokupa Kecamatan Tombariri Kabupaten Minahasa Provinsi Sulawesi Utara dan ditemukan 5 spesies bintang laut (Umboh, 2016) dan di Pantai Bahowo Kecamatan Bunaken, Sulawesi Utara oleh Maabuat (2005) dilihat spesies Linckia laevigata dan didapatkan tiga macam warna dengan jumlah 25 individu.

Sebagai salah satu Pantai yang baru diresmikan sebagai tempat wisata, Pantai Bahowo Kecamatan Bunaken, Sulawesi Utara dapat mengalami resiko penurunan keanekaragaman jenis bintang laut, bilamana peningkatan aktivitas manusia (wisatawan) tidak diiringi dengan pelestarian lingkungan, begitu pula dengan adanya pembangunan dermaga yang masih akan dilanjutkan. Informasi mengenai keanekaragaman jenis bintang laut di Pantai Bahowo juga masih kurang sehingga perlu dilakukan penelitian. Berdasarkan hal tersebut, dipandang perlu dilakukan penelitian tentang bintang laut di Pantai Bahowo Kecamatan Bunaken, Kota Manado, Sulawesi Utara.

menggunakan metode transek kuadrat. Terdapat tiga transek yang telah ditentukan dengan jarak masing-masing 100 meter. Pada setiap transek ditarik garis lurus dengan panjang $100 \mathrm{~m}$ kearah laut dengan menggunakan roll meter. Dalam satu transek terdapat sepuluh plot jarak antar plot $10 \mathrm{~m}$. Proses pengambilan sampel ini dilakukan pada saat air laut mengalami surut sekitar jam 10.00 sampai jam 12.30. Sampel yang telah terkumpul dibersihkan dan diawetkan 
menggunakan alkohol 70\%. Pemberian alkohol bertujuan untuk mengawetkan sampel agar tidak busuk.

\section{Analisis Data}

Identifikasi jenis bintang laut dilakukan dengan bantuan kepustakaan Clark dan Rowe (1971), Linnaeus (1758), Lariman (2011), dan Gray (1840). Untuk mengetahui keanekaragaman jenis bintang laut (Asteroidea), maka data yang diperoleh di lapangan dianalisis dengan menggunakan beberapa rumus:

Kelimpahan relatif menurut (Cox, 1967):

Kelimpah relatif (\%)

$=\frac{\text { Jumlah individu satu spesies }}{\text { Jumlah individu seluruh spesies }} \times 100 \%$

Indeks Keanekaragaman menurut ShannonWiener (Krebs, 1985) :

$$
H^{\prime}=-\sum p i \ln p i
$$

Keterangan:

$\mathrm{Pi}=\sum \mathrm{ni} / \mathrm{N}$

$H^{\prime}=$ Indeks Keanekaragaman Shannon-

Wiener

$\mathrm{Pi}=$ Jumlah individu suatu spesies/jumlah total seluruh spesies $\mathrm{ni}=$ Jumlah individu spesies ke-i $\mathrm{N}=$ Jumlah total individu Indeks Kemerataan (Ludwig dan Reynolds, 1998) :

$$
e=\frac{H^{\prime}}{\ln S}
$$

Keterangan :

e : Indeks Kemerataan

$\mathrm{H}^{\prime}$ : Indeks keanekragaman

$\mathrm{S}$ : Jumlah spesies

Indeks kekayaan (Margalef, 1963 dalam Elliot, 1977) :

Keterangan :

$$
R=\frac{(S-1)}{\ln n}
$$

$\mathrm{R}$ : Kekayaan spesies
$\mathrm{S}:$ Jumlah spesies

$\mathrm{n}$ : Jumlah individu

\section{HASIL DAN PEMBAHASAN}

Deskripsi Lokasi Penelitian

Secara umum kondisi lokasi penelitian terbagi atas tiga jenis ekosistem yaitu daerah mangrove, daerah pasir yang ditumbuhi lamun dan daerah terumbu karang yang cukup luas. Transek satu adalah daerah yang dekat dengan dermaga Pantai Bahowo, kegiatan masyarakat masih cukup banyak dan juga didapatkan ada masyarakata dan wisatawan yang membuang sampah di daerah ini. Di transek satu ini juga menjadi tempat parkir kapal nelayan, dan tempat melintas untuk ke pemukiman warga. Transek dua adalah daerah yang lumayan jauh dari Dermaga Bahowo, kegiatan masyarakat kurang. Begitu juga dengan transek tiga. Transek tiga adalah daerah yang paling jauh dari Dermaga Bahowo dan kegiatan masyarakatpun sangat kurang.

\section{Jumlah Spesies dan Individu Bintang Laut}

Berdasarkan hasil penelitian di Pantai Bahowo Kecamatan Bunaken, Sulawesi Utara diperoleh lima spesies bintang laut yaitu Archaster typicus, Linckia laevigata, Protoreaster nodosus, Culcita novaeguineae dan Nardoa tuberculata (Tabel 1). Jumlah individu tertinggi diantara ketiga transek adalah transek tiga (Tabel 1). Hal ini dikarenakan kurangnya aktivitas manusia dan jauhnya transek ketiga dari lokasi Dermaga Bahowo. Sedangkan jumlah 
individu yang paling rendah terdapat di transek satu. Transek satu terletak dekat dengan Dermaga Bahowo, selain itu menjadi tempat parkir maupun tempat kapal nelayan melintas. Manusia diduga berperan dalam mengurangi jumlah jenis bintang laut, karena banyak jenis bintang laut diambil hidup maupun mati untuk akuarium, atau hiasan (Emmens, 1990).

Tabel 1. Jumlah Spesies dan Jumlah Individu Bintang Laut yang ditemukan di Pantai Bahowo, Kecamatan Bunaken, Kota Manado, Sulawesi Utara.

\begin{tabular}{ccccc}
\hline \multirow{2}{*}{ No } & Nama Spesies & \multicolumn{3}{c}{ Transek } \\
\cline { 3 - 5 } & & 1 & 2 & 3 \\
\hline 1 & Archaster typicus & 4 & 5 & 9 \\
2 & Linckia laevigata & 2 & 4 & 5 \\
3 & Protoreaster nodosus & 3 & 15 & 20 \\
4 & Culcita novaeguineae & 0 & 2 & 2 \\
5 & Nardoa tuberculata & 0 & 1 & 5 \\
\hline Jumlah Spesies & & 3 & 5 & 37 \\
Jumlah individu & & 9 & 27 & \\
TOTAL Individu & & & 73 Individu \\
\hline
\end{tabular}

Spesies yang tertinggi kedua setelah $P$. nodosus adalah spesies A. typicus dengan jumlah 18 individu, spesies ini dalam satu plot terdapat tiga sampai lima individu, spesies ini juga hidup secara berkelompok di habitat pasir. Dibandingkan dengan jumlah individu di Pantai Meras, Kecamatan Bunaken, Sulawesi Utara oleh Rompis (2013) ditemukan A. typicus berjumlah 60 individu yang terdapat pada substrat berpasir. Maka, jumlah individu spesies A. typicus yang ada di Pantai Bahowo lebih sedikit. Namun lebih tinggi dari jumlah individu di perairan Pulau Pucung oleh Hidayat (2017) yang hanya menemukan 16 individu spesies A. typicus. Spesies yang paling rendah adalah spesies $N$. tuberculata yang hanya berjumlah dua individu, spesies ini sulit ditemukan di lokasi penelitian karena spesies ini hidup soliter atau hidup sendiri, dan tidak berkelompok. Hasil yang sama juga ditemukan oleh Ramadhan (2008) di Perairan Pulau Pari, Kepulauan Seribu, terdapat dua spesies $N$. tuberculata yang hidup secara soliter atau tidak sanggup bertahan karena berbagai faktor eksternal (misalnya, penurunan kualitas habitat).

Tabel 2. Bintang Laut berdasarkan habitat di Pantai Bahowo, Kecamatan Bunaken, Kota Manado, Sulawesi Utara.

\begin{tabular}{ccccc}
\hline No & Nama Spesies & Pasir & Lamun & Karang \\
\hline 1 & Archaster typicus & + & - & - \\
2 & Linckia laevigata & - & + & + \\
3 & Protoreaster nodosus & + & + & + \\
4 & Culcita novaeguineae & - & + & +
\end{tabular}




\begin{tabular}{cr}
5 & Nardoa tuberculata \\
\hline Spesies yang terdistribusi pada semua
\end{tabular}
substrat yaitu $\mathrm{P}$. nodosus, sedangkan spesies L. laevigata, $C$. novaeguineae dan $N$. tuberculata hanya terdapat di dua substrat yaitu substrat lamun dan karang. Berbeda dengan Budiman (2014) yang melaporkan bahwa di Pantai Basaan Satu Kecamatan Ratatotok, spesies $P$. nodosus hanya terdistribusi di habitat lamun dan karang sedangkan spesies L. laevigata, dan $N$. tuberculata hanya terdapat di daerah karang. Rompis (2013) mengemukakan bahwa di Pantai Meras, Kecamatan Bunaken, Sulawesi Utara spesies $P$. nodosus terdistribusi di semua habitat yaitu habitat pasir, lamun dan karang sedangkan spesies L. laevigata hanya terdapat di habitat pasir dan lamun.

Spesies bintang laut yang ada di Pantai Bahowo sebagian besar juga menyukai habitat karang (Tabel 2) hal ini dikarenakan, secara ekologis bintang laut berperan dalam ekosistem terumbu karang umumnya sebagai pemakan detritus dan predator. Spesies $A$. typicus yang ada di Pantai Bahowo, hanya terdapat di daerah berpasir dan berlumpur karena habitat dari spesies ini hanya ditemukan di daerah berpasir. Di Pantai Meras, Kecamatan Bunaken, Sulawesi Utara, oleh Rompis (2013) juga menemukan hasil yang sama bahwa spesies A. typicus hanya terdapat di habitat berpasir.

Kelimpahan Relatif Bintang Laut
Kelimpahan relatif yang paling tinggi ialah spesies $P$. nodosus dengan jumlah individu 38 dan nilai kelimpahan relatifnya 52,05. Spesies dengan kelimpahan relatif tertinggi kedua adalah spesies A. typicus dengan nilai kelimpahan relatifnya 15,07. Kelimpahan relatif yang paling rendah ialah spesies $N$. tuberculata dengan jumlah individu dua dan nilai kelimpahan relatifnya 2,74. Dari hasil yang telah didapatkan, nilai kelimpahan relatif didukung oleh tinggi rendahnya jumlah individu dari satu jenis, saat jumlah individu rendah nilai kelimpahan relatifnya juga rendah seperti $C$. novaeguineae dan $N$. tuberculata. Jumlah individu yang sedikit dikarenakan kedua spesies tersebut sangat sulit ditemukan di lokasi penelitian dan juga cara hidup kedua spesies tersebut soliter atau hidup sendiri.

\section{Indeks Keanekaragaman, Kemerataan dan Kekayaan}

Nilai Indeks keanekaragaman yaitu $\mathrm{H}^{\prime}=1,23$. Hasil menunjukkan bahwa indeks keanekaragaman di Pantai Bahowo ini termasuk keanekaragaman sedang. Tingkat keanekaragaman sedang menunjukkan, produktivitas cukup, kondisi ekosistem cukup seimbang dan tekanan ekologis sedang. Tingkat keanekaragaman sedang disebabkan karena sangat sedikit jumlah individu dan jumlah spesies yang didapatkan. Dimana, jumlah spesies hanya berjumlah lima.

Tabel 3. Nilai Indeks Keanekaragaman (H'), Kemerataan (E) dan Kekayaan (R) Bintang Laut di Pantai Bahowo, Kecamatan Bunaken, Sulawesi Utara. 
Nilai indeks kemerataan di Pantai Bahowo yaitu 0,76 (Tabel 5).Nilai indeks kemerataan ini menunjukkan bahwa jenis bintang laut yang ada di Pantai Bahowo mengalami penyebaran yang merata. Odum (1971) menyatakan bahwa sebaran fauna seimbang atau merata apabila mempunyai nilai indeks kemerataan jenis yang berkisar antara 0,6-0,8. Jika dilihat (Lampiran 1) jumlah setiap jenis bintang laut bisa

Deskripsi Spesies yang Ditemukan: Archaster typicus (Clark dan Rowe, 1971): A.typicus yang ditemukan di Pantai Bahowo hidup di daerah pasir berlumpur yang ditumbuhi mangrove. Tubuhnya berwarna kecoklatan bagian dorsal berwarna putih, mempunyai lima lengan dan mempunyai duri-duri halus yang berwarna putih.Spesies ini biasanya hidup berkelompok tiga sampai lima spesies. Saat penelitian, tidak ditemukan spesies ini hidup soliter atau hidup sendiri.

\section{Linckia laevigata (Linnaeus, 1758):}

L. laevigata yang ditemukan di Pantai Bahowo hanya ditemukan satu warna yaitu warna biru. Spesies ini mempunyai lima lengan dengan bentuk tubuh bintang. Ujung lengan berbentuk tumpul. $L$. laevigata hidup di daerah lamun dan terumbu karang. digolongkan merata. Misalnya spesies $P$. nodosus, spesies ini di transek tiga ditemukan dengan jumlah yang hampir. Nilai indeks kekayaan di Pantai Bahowo yaitu 0,93 (Tabel 5). Nilai indeks kekayaan di Pantai Bahowo sangat rendah. Secara umum, kekayaan jenis suatu komunitas sangat dipengaruhi oleh banyak faktor yang saling berkaitan terutama oleh faktor kualitas lingkungan, baik fisik maupun kimia (Yusron, 2013).

Spesies yang berada di daerah terumbu karang cenderung lebih kecil bentuk tubuhnya dari spesies yang ada di daerah lamun. Hal ini bisa disebabkan karena daerah lamun Pantai Bahowo memiliki makanan yang cukup melimpah. Spesies ini di dapati tergenang dan seringkali menempel di daerah karang.

\section{Protoreaster nodosus (Linnaeus, 1758):}

$P$. nodosus yang ditemukan di Pantai Bahowo memiliki warna yang paling dominan yaitu berwarna orange dan memiliki duri-duri tumpul yang berwarna hitam diatas tubuhnya. Spesies ini hidup di daerah berpasir, lamun, dan terumbu karang. Saat penelitian $P$. nodosus selalu menempati daerah yang tergenang air. Saat penelitan spesies $P$. nodosus ada yang ditemukan sementara berjalan.
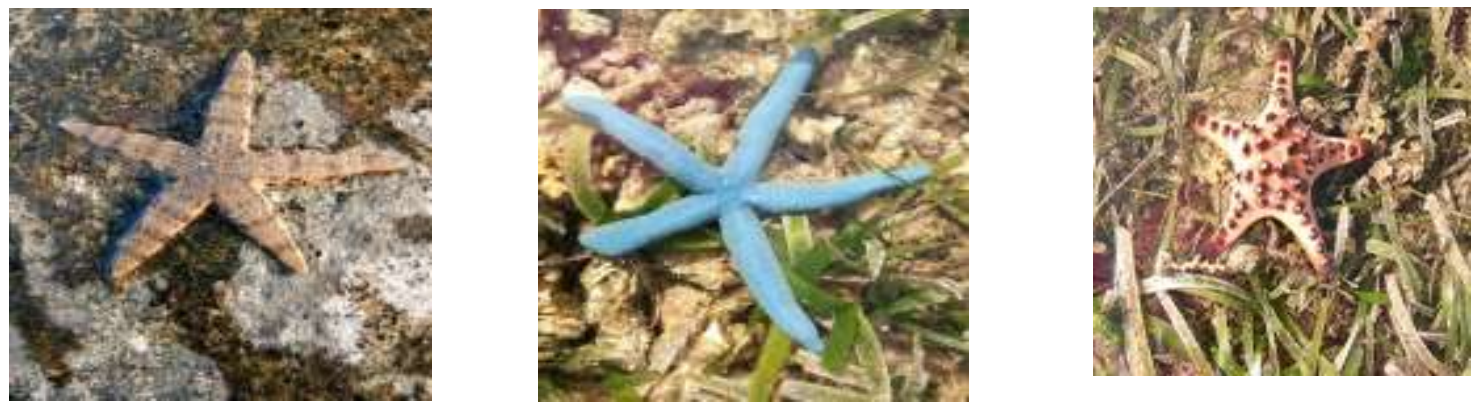
Gambar 1. Archaster typicus Gambar 2. Linckia laevigata Gambar 3. Protoreaster nodosus

Culcita novaeguineae (Lariman, 2011):

C. novaeguineae yang ditemukan di lokasi penelitian memiliki bermacam-macam warna seperti warna kuning kehijauan bercampur hitam dan warna hijau kehitaman. Warna spesies ini sangat bervariasi dan mempunyai bintik yang lebih gelap dan lebih terang dari coklat, orange, kunng, dan hijau. Pada saat penelitian spesies ini ditemukan menempati daerah yang tergenang air.

Nardoa tuberculata (Gray, 1840):

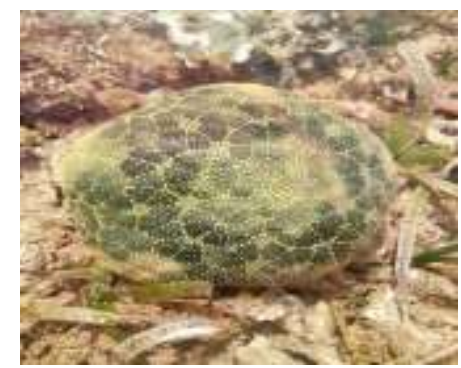

Gambar 4. Culcita novaeguineae

\section{KESIMPULAN}

Pada penelitian di Pantai Bahowo, Kecamatan Bunaken Sulawesi Utara, didapatkan indeks keanekaragaman sedang. Nilai indeks keanekaragaman yaitu 1,23. Ditemukan lima spesies, Archaster typicus, Linckia laevigata, Protoreaster nodosus, Culcita novaeguineae dan Nardoa tuberculata dengan jumlah 73 individu.

\section{DAFTAR PUSTAKA}

Aziz, A . 1996. Makanan dan Cara Makan Berbagai Jenis Bintang Laut. Majalah Oceano.

Budiman, 2014. Keanekaragaman Echinodermata di Pantai Basaan Satu
N. tuberculata sangat sulit ditemukan di Pantai Bahowo, hal itu bisa disebabkan karena cara hidup yang soliter atau sendiri. Selain itu, bisa disebabkan karena kurangnya kemampuan untuk beradaptasi. N. tuberculata ditemukan di daerah lamun dan terumbu karang. Spesies ini memiliki bintil-bintil yang terdapat pada bagian atas tubuhnya, mempunyai warna kecoklatan dan bintil-bintil berwarna putih. Berbentuk bintang dan mempunyai lima lengan.

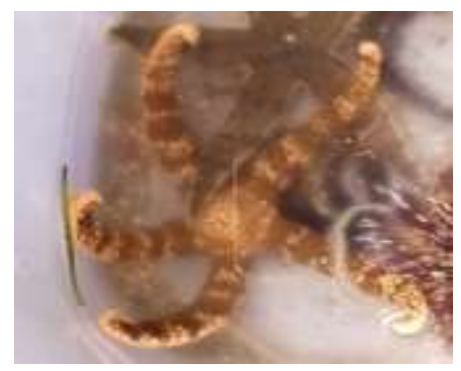

Gambar 5. Nardoa tuberculata

Kecamatan Ratatotok Sulawesi Utara. [Skripsi]. UNSRAT. Manado.

Clark, A.M. and F. W. E. Rowe 1971. Monograph of shallow water Indo West Pacific Echinoderms. London.

Cox, G. W. 1967. Laboratory Manual of General Ecology. Brown Company Publisher, USA.

Elliott, J. M. 1997. Some Methods for the Statistical Analysis of Samples of Benthic Invertebrates. Freshwater Biological Association.

Emmens, C.W. 1990. Marine aquaria and miniature reef, the fishes, the invertebrates, the techniques. TFH Pub. Inc. USA. 
Gray, 1840. World Asteroidea Database. Maabuat, P. V. 2005. Distribusi, Kelimpahan, Accessed through: World Register ofMarineSpecies.http://www.marine species.org/aphia.php? $p=$ taxdetails \&id $=212318 . \quad[\mathrm{Di}$ akses 17 September 2018]. Dan Variasi Morfologi Bintang Laut Linckia laevigata Di Pantai Bahowo, Tongkaina. Skripsi. UNSRAT. Manado.

Puspitasari, Suryanti, dan Ruswahyuni. 2012. Hidayat, W. 2017. Studi Sebaran Echinodermata Di Zona Litoral Pulau Pucung. [Skripsi]. FPIK-UMRAH.

Iken K, Konar B, Benedetti-Cecchi L, CruzMotta JJ, Knowlton A, Pohle G, Mead A, Miloslavich P, Wong M, Trott T, et al. 2010. Large-scale spatial distribution patterns of echinoderms in nearshore rocky habitats. PLoS ONE.5(11).

Studi Taksonomi Bintang Laut (Asteroidea, Echinodermata) Dari Kepulauan Karimunjawa, Jepara. Journal of Management of Aquatic Resources. 1(1): 6.

Ramadhan, M. F. 2008. Sebaran Lokal Asteroidea (Echinodermata) Di Pulau Tikus, Kepulauan Seribu. [Skripsi]. IPB. Bogor.

Rompis R (2013) Diversitas Echinodermata di Pantai Meras, Kecamatan Bunaken, Sulawesi Utara. Jurnal Biologos 3(1): 26-30.

Lariman, 2011. Keanekaragaman Filum Echinodermata di Pulau Beras Basah Kota Bontang Kalimantan Timur. 10(2). FMIPA Universitas Mulawarnan.

Linnaeus, 1758. World Echinoidea Database. Accessed through: world Register of MarineSpecies.http://www.marinesp ecies.org/aphia.php? $p=$ taxdetail \&id $=2$ 1328. [Di akses 17 September 2018].

Ludwiig, J. A. and J. F. Reynolds. 1998. Statistic Ecology. A Wiley Interscience Publication. John Wiley and Sons New York.

Susantie, D. 1997. Beberapa Aspek Reproduksi Bintang Laut Protoreaster nodosus. Makalah. FPIKUNSRAT. Manado.

Umboh, S.C. 2016. Komunitas Bintang Laut Di Perairan Pantai Desa Mokupa Kecamatan Tombariri Kabupaten Minahasa Provinsi Sulawesi Utara. Jurnal Ilmiah. 4(1): 41.

Yusron, E. 2013. Biodiversitas Fauna Echinodermata (Holothuroidea, Echinoidea, Asteroidea dan Ophiuroidea) di Perairan Pulau Lombok, Nusa Tenggara Barat. Zoo Ind. 22(1):1-10. 